$\mathrm{DE}$

M E D I C I N A

T R O P I C A L

$\mathrm{DE}$

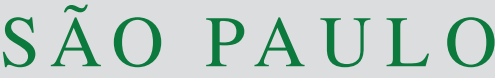

JOURNAL OF THE SÃO PAULO INSTITUTE OF TROPICAL MEDICINE

${ }^{1}$ Hospital Universitario San Vicente Fundación, Grupo Biología Molecular e Inmunología de Trasplantes, Medellín, Colombia

2Universidad de Antioquia, Escuela de Microbiología, Medellín, Colombia

${ }^{3}$ Universidad de Antioquia, Facultad de Medicina, Medellín, Colombia

Correspondence to: Adrían Peñata Hospital Universitario San Vicente Fundación, Calle 64 \# 51D - 154, 054010, Medellín, Antioquia, Colombia Tel: +5734 4441333 ext 3106

E-mail: carlosadrianpb @gmail.com

Received: 13 April 2020

Accepted: 15 September 2020

\section{Molecular diagnosis of meningitis and meningoencephalitis with an automated real-time multiplex polymerase chain reaction in a tertiary reference complex in Medellín, Colombia}

\author{
Adrián Peñata ${ }^{\circledR}$, Santiago Mesa ${ }^{\circledR 2}$, Ana Leal ${ }^{\circledR}$, Tatiana Castaño $^{(1}$, Julián \\ Bustamante ${ }^{(1)}$, Ospina Sigifredo ${ }^{(1)} 3$
}

\section{ABSTRACT}

Meningoencephalitis is a syndrome of multiple etiologies associated with important morbidity and mortality. It may be caused by various infectious agents (viruses, bacteria, parasites and fungi). Establishing the etiology of meningoencephalitis is crucial for early and specific treatment. Molecular assays such as the multiplex polymerase chain reaction (PCR) offer an alternative in diagnosing central nervous system infections. This study aimed to describe the performance of an automated multiplex molecular test from patients with suspected meningitis and meningoencephalitis in a tertiary referral complex in Medellin, Colombia. Thus, a prospective study was performed in 638 cerebrospinal fluid samples from January 2017 to July 2019. Molecular detections were carried out by means of the FilmArray ${ }^{\circledR}$ Meningitis/Encephalitis (M/E) Panel from bioMérieux, France, and by conventional tests. Univariate analyses for microbiological and demographic characteristics were performed. Accuracy of the bacterial/fungal PCR assay compared to cultures was also performed. Among patients, $57.7 \%$ were male, the median age was 24 (IQR: 6 - 47) years old. The overall positivity was $15.2 \%$ (97 detections) and viruses were detected in $45.5 \%$ of the samples, bacteria in $43.5 \%$ and fungi in $10.8 \%$. The most frequent etiological agents were: Streptococcus pneumoniae (16\%), Cryptococcus neoformans/gatti $(11.3 \%)$ and Herpes simplex virus (10.3\%). Four double detections were found. Almost half of positive detections were in patients under 15 years old. This molecular approach is reliable and easily implantable into a laboratory routine, increasing the capacity of detection of bacterial and viral causative agents of meningitis, possibly playing a relevant role in the clinical context.

KEYWORDS: Meningitis. Meningoencephalitis. Diagnosis. Multiplex PCR. Colombia.

\section{INTRODUCTION}

Meningitis is an inflammatory condition involving the membranes covering the central nervous system (CNS) that can be caused by bacteria, viruses, parasites and fungi ${ }^{1}$. According to the Global Burden of Diseases study, in 2016 there number of incident cases were estimated at 2.82 million while the number of meningitis deaths were estimated at 318,400 cases. Most deaths occurred in countries of low sociodemographic index as the ones in sub-Saharan Africa, in which the incident cases are the highest, 207.4 per 100,000 inhabitants ${ }^{2}$. In the United States, every year approximately 4,100 cases of bacterial meningitis are diagnosed leading to 500 deaths. On the other hand, viral etiology is more common in patients under 15 years old, with 20,000 cases and an average of 1,400 deaths per year ${ }^{1,3}$. 
In Colombia, historical incident cases of bacterial meningitis are in the range of $0.06-0.28$ per 100,000 inhabitants for Haemophilus influenzae, Streptococcus pneumoniae and Neisseria meningitis, with a lethality rate between $3.5-21 \%$. Data from the Laboratory surveillance SIREVA network, in Latin America and the Caribbean showed that $S$. pneumoniae serotype 14 was the most frequently isolated $(21.1 \%)$, especially in children under 6 years of age (29.1\%). Regarding the viral etiology, until today, the magnitude of the problem is unknown due to the underreporting of cases to the public epidemiological surveillance system.

In Colombia, during 2004, an epidemic of aseptic meningitis was registered in Antioquia, with a total of 263 reported cases, $77 \%$ of them (160/263) in Medellin, and the National Institute of Health demonstrated that four of them were caused by Echoviruses $30^{5}$.

From the Public Health point of view, rapid diagnosis and treatment of CNS infections are crucial to impact the morbidity and mortality. In addition, in many areas around the world, particularly in rural areas, the capacity to perform traditional diagnostic assays, such as culture or the detection of bacterial antigens is limited or nonexistent, leading to delayed or absence of the etiological diagnosis ${ }^{2}$. Traditionally, laboratory diagnosis of meningitis have included examination of cerebrospinal fluid (CSF) specimens for cells count, measurement of glucose and protein levels, and the gram staining; these tests may suggest the type of infection but they are not specific. Bacterial cultures from CSF can provide the diagnosis, however, it may take several days and it has critical limitations such as the sensitivity to detect some pathogens ${ }^{1}$. Regarding viral detection, before the development of molecular methods such as Polymerase Chain Reaction (PCR), the isolation of pathogens traditionally relied on cell culture, despite the long period required to release the result, aside from the need of technical expertise ${ }^{6}$.

Recently, molecular tests allowing a syndromic approach to diagnosis of meningitis have become available in Colombia, such as the FilmArray ${ }^{\circledR}$ Meningitis/Encephalitis (FA-M/E) panel (BioFire Diagnostics, bioMérieux, Salt Lake City, USA). This is a molecular tool that allows the simultaneous detection of 14 pathogens (bacteria, viruses and one fungus). The entire process is fully automated and takes approximately one hour to release the results ${ }^{7}$. In this study, we have documented the performance of FA-M/E in CSF samples of patients with suspected meningitis or meningoencephalitis infections in the context of a tertiary referral hospital, comparing the results obtained by this molecular method with traditional testing.

\section{MATERIALS AND METHODS}

\section{Study design}

A prospective study of consecutive samples from 638 patients with clinical suspicion of neuroinfections was conducted between January 2017 to July 2019 in the teaching Hospital San Vicente Fundacion in Medellin, the second largest city of Colombia. It is a tertiary health institute and a reference center for infectious diseases, with a total of 819 beds of capacity.

The criteria for suspect meningitis infection and the inclusion of the patients followed the institutional clinical guideline, with findings such as headache, nuchal rigidity, fever and altered consciousness ${ }^{4}$. The patients must have molecular and microbiological tests requested by the attending physician and there was no age restriction.

\section{Clinical and epidemiologic information}

Clinical, microbiological and demographic information were obtained from the electronic medical records and from the laboratory database of the hospital. The studied variables were gender, age, comorbidities and microbiological/ molecular results.

\section{Conventional assays}

CSF samples were collected in three sterile tubes (1-3 mL), which were used for the biochemical analysis, as well as microbiological and molecular tests.

\section{Cellular and chemical parameters}

Total protein and glucose, was determined by benzethonium cholire and hexokinase/G-6-PDH, respectively (Architect, Abbott, IL, USA); the total White Blood Cell $(\mathrm{WBC}) / \mathrm{mm}^{3}$ was quantified in non-centrifuged CSF using a Neubauer chamber.

\section{Gram staining}

After centrifugation (1,300 g for $10 \mathrm{~min})$, the smear was prepared by placing 1-2 drops of the sediment on a glass slide, air-dried, and subsequently, Gram-stained by PREVI $^{\circledast}$ Color Gram (bioMerieux, Inc., Durham, NC, USA), following the instructions of the manufacturer.

\section{Bacterial/fungal culture}

Bacterial cultures were performed on every collected 
specimen using the laboratory standard procedures. Solid media (blood, chocolate, and Sauboraud agar) and a thioglycolate broth were incubated at $37^{\circ} \mathrm{C}$ in $5 \% \mathrm{CO} 2$ for $5 \mathrm{~d}$. Microbial isolates were identified by a matrix-assisted laser desorption ionization-time of flight mass spectroscopy (MALDI-TOF MS) analysis. In addition, a lateral flow assay for a cryptococcal antigen $(\mathrm{CrAg})$ was performed in patients with suspicion of fungal disease in the CNS.

\section{Molecular test}

The FA-M/E was performed in accordance with the manufacturer's instructions. Briefly, a total of $200 \mu \mathrm{L}$ of each CSF sample were required to run the assay; the test process includes a nucleic acid extraction/purification stage, a first round of highly multiplexed amplification of all targets, followed by a nested-amplification of each target triplicated tested on the array. The FilmArray ${ }^{\circledR}$ software system automatically interprets the three results obtained as three independent melting curves to give a unique final result ${ }^{7}$. The master list includes: E. coli Kl, H. influenzae, L.monocytogenes, N. meningitidis, S.agalactiae, S. pneumoniae, CMV (Cytomegalovirus), EV (Enterovirus), Herpes Simplex Virus 1 and 2 (HSV-1 and HSV-2), Human Herpes virus 6 (HHV-6), Human Parechovirus (HPeV), Varicella-Zoster Virus (VZV) and C. neoformans/gatti.

\section{Date analysis}

All data were entered into a Microsoft Office Excel 2016 database. Statistical analysis was performed using R (version 3.6.3, The R Foundation for Statistical Computing, Vienna, Austria). Demographic data are presented as descriptive statistics. Sensitivity and Specificity values were calculated in a $95 \%$ confidence interval (CI) for bacterial and fungi detections, using CSF culture as the reference (standard) with Epidat (version 4.2, Conselleria de Sanidade, Xunta de Galicia, Spain). Nonparametric Kruskal-Wallis test was used to compare the differences between cellular/chemical parameters (CSF cells count, protein levels and glucose) and FA-M/E (bacterial, fungal and viral detections); results were considered statistically significant at $\mathrm{p} \leq 0.05$.

\section{Ethical considerations}

The ethical approval was obtained from the institutional review committee according to the technical-administrative procedures for health research included in the resolution $\mathrm{N}^{\circ} 8430$ of the Ministry of Health of Colombia ${ }^{8}$. Additionally, this study complied with the World Medical
Association Declaration of Helsinki regarding the ethical conducts of research involving human subjects.

\section{RESULTS}

A total of 695 consecutive samples were included in the study, and 57 were excluded due to inconsistencies in culture results or in cellular and chemical parameters. In addition, during the study period, 11 samples were unsuccessful due to flaws in the internal pouch control, but were reprocessed. A total of 638 samples met all enrollment criteria, and were analyzed. Among the patients, $83.4 \%$ (362) were male, the median age was 24 years (IQR: 6-47), ranging from one day to 87 years old; the most common comorbidities were CNS-associated diseases, while the second most frequent comorbidity was HIV infection, but only 250 patients were subjected to the HIV test (HIV antibodies detection or viral load). Other characteristics of patients are shown in Table 1.

Table 1 - Demographic and clinical characteristics of patients with suspected meningitis and meningoencephalitis, Hospital Universitario San Vicente Fundacion, Medellin, 2017-2019

\begin{tabular}{lcc}
\hline \multirow{2}{*}{ Characteristicss } & \multicolumn{2}{c}{ Total $(\mathrm{n}=638)$} \\
\cline { 2 - 3 } Gender & $\mathrm{n}$ & $\%$ \\
$\quad$ Males & 362 & 83.4 \\
Age (years) & \\
$\quad<1$ & 58 & 9.1 \\
1 a 14 & 184 & 28.8 \\
15 a 35 & 170 & 26.6 \\
36 a 64 & 162 & 25.4 \\
$>65$ & 64 & 10.0 \\
Comorbidity & & \\
Associated to CNS & 395 & 619 \\
HIV infection & 50 & 7.8 \\
Sepsis & 27 & 4.2 \\
\hline
\end{tabular}

CNS = Central Nervous System; HIV = Human Immunodeficiency Virus

The overall positivity of the multiplex test was $15.2 \%$ (97 detections), and Streptococcus pneumoniae was the most frequent pathogen with $16.5 \%$ (16); among viruses Herpes simplex 1 was the most commonly detected. Four samples presented double detections (Table 2). Around 50\% of detections were in patients under 15 years old. In this group, the most commonly detected organisms were HHV-6 and Neisseria meningitidis. Among those aged 25 or older, $C$. neoformans/gatti and S. pneumoniae were the predominant pathogens (Figure 1). The 97 positive detections according 
Table 2 - Detected pathogens by Biofire ${ }^{\circledR}$ FilmArray ${ }^{\circledR}$ Meningitis/Encephalitis, Hospital Universitario San Vicente Fundacion, Medellin, 2017-2019.

\begin{tabular}{|c|c|c|c|c|c|c|c|c|c|}
\hline Microorganism & $\mathrm{n}$ & $\%$ & 0.0 & $2.0 \quad 4.0$ & 6.0 & $10.0 \quad 12.0$ & 14.0 & 16.0 & 18.0 \\
\hline Streptococcus pneumoniae & 16 & 16.5 & & & & & & & \\
\hline Cryptococcus neoformans/gatti & 11 & 11.3 & & & & ב & & & \\
\hline HSV 1 & 10 & 10.3 & & & & & & & \\
\hline Varicella zoster virus & 8 & 8.2 & & & & & & & \\
\hline HHV 6 & 8 & 8.2 & & & & & & & \\
\hline Escherichia coli K1 & 7 & 7.2 & & & & & & & \\
\hline Neisseria meningitidis & 7 & 7.2 & & & 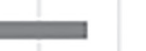 & & & & \\
\hline Enterovirus & 7 & 7.2 & - & & & & & & \\
\hline Haemophilus influenzae & 6 & 6.2 & & & & & & & \\
\hline CMV & 4 & 4.1 & - & & & & & & \\
\hline HSV 2 & 4 & 4.1 & 口 & & & & & & \\
\hline Listeria monocytogenes & 3 & 3.1 & 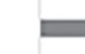 & 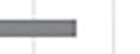 & & & & & \\
\hline Parechovirus & 1 & 1.0 & 曰 & & & & & & \\
\hline Streptococcus agalactiae & 1 & 1.0 & $\square$ & & & & & & \\
\hline H. influenzae/CMV & 1 & 1.0 & $\square$ & & & & & & \\
\hline S. agalactiae + E. coli $\mathrm{K} 1$ & 1 & 1.0 & $\square$ & & & & & & \\
\hline Enterovirus + HHV 6 & 1 & 1.0 & 曰 & & & & & & \\
\hline E.coli K1 + HSV 1 & 1 & 1.0 & ש & & & & & & \\
\hline Total & 97 & 100 & & & & & & & \\
\hline
\end{tabular}

Virus $=45,5 \% ;$ Bacteria $=43,5 \% ;$ Fungi $=10,8 \%$

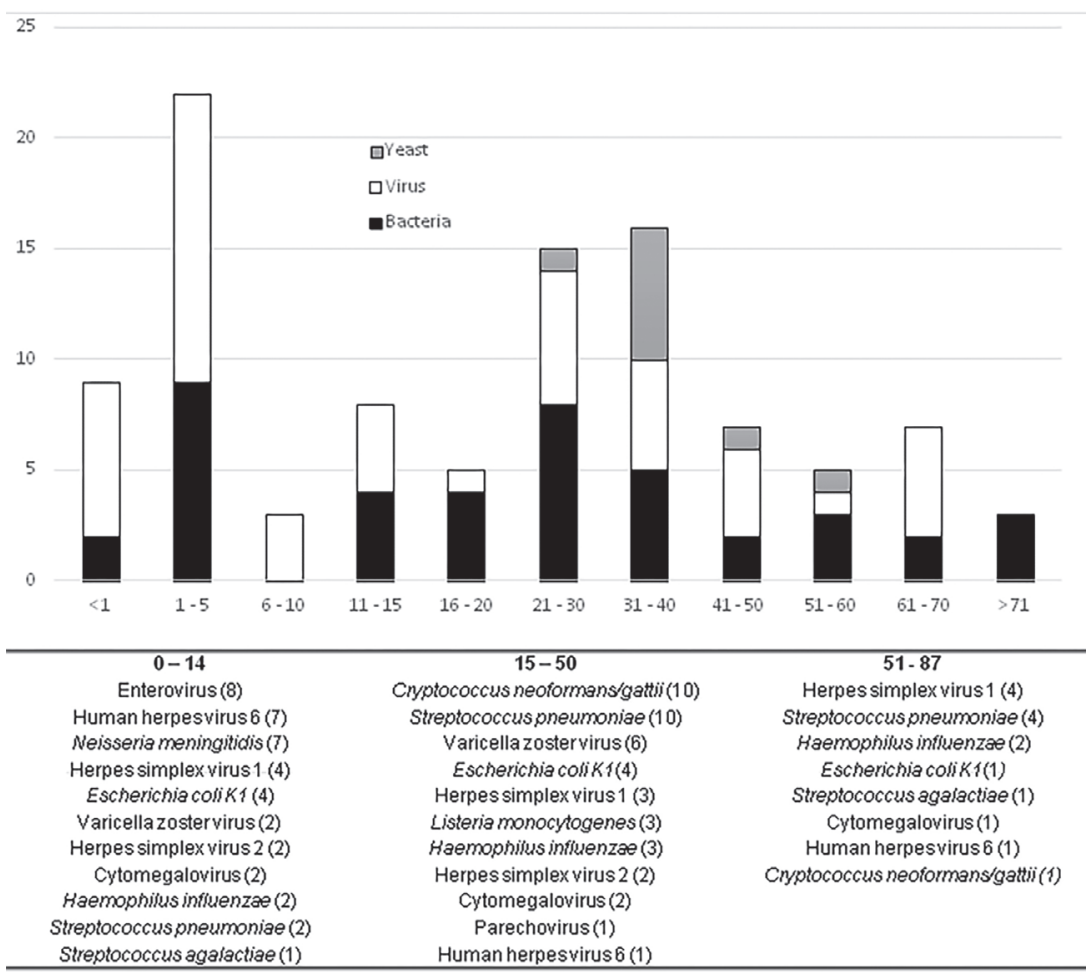

Figure 1 - Distribution of pathogens detected by the Biofire ${ }^{\circledR}$ FilmArray ${ }^{\circledR}$ Meningitis/Encephalitis according to the age groups (years), Hospital Universitario San Vicente Fundacion, Medellin, 2017-2019. 
Table 3 - Cellular and chemical concentration of CSF analytes among positive detections by Biofire ${ }^{\circledR}$ FilmArray ${ }^{\circledR}$ Meningitis/ Encephalitis.

\begin{tabular}{lcccc}
\hline & \multicolumn{3}{c}{ Positive detections } \\
\cline { 2 - 3 } Total = 93 & Bacterial $(\mathrm{n}=40)$ & Fungal $(\mathrm{n}=11)$ & Viral $(\mathrm{n}=42)$ & \\
\hline CSF parameters ${ }^{b}$ & & & \\
Protein $(\mathrm{mg} / \mathrm{dL})$ & $196.8(53.1-400)$ & $63.5(32.1-188)$ & $75(36.8-138)$ & 0.01 \\
Glucose $(\mathrm{mg} / \mathrm{dL})$ & $19.5(4-44.7)$ & $34(11-42)$ & $51(42-72)$ & 0,00 \\
White blood cells $\left(\mathrm{mm}^{3}\right)$ & $169(4.2-1,177)$ & $15(2.25-276.5)$ & $9(0-236)$ & 0.03 \\
Polymorphonuclear $\left(\mathrm{mm}^{3}\right)$ & $75(0.2-1,692)$ & $12(1.5-200)$ & $3(0-82.5)$ & 0.02 \\
$\quad$ Mononuclear $\left(\mathrm{mm}^{3}\right)$ & $22.5(0-79.5)$ & $3.5(0.5-102)$ & $0(0-30.5)$ & 0.06 \\
\hline
\end{tabular}

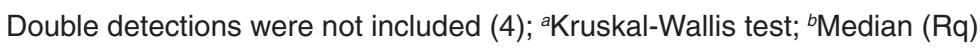

to the HIV status were: $55 \%$ (54) in HIV-negative patients, $19.5 \%$ (19) in HIV-positive ones, while in the remaining $24 \%$ (24) of the patients, the HIV status was not evaluated. C. neoformans/gatti (8), VZV (4), CMV (3) were most frequently detected in HIV-positive patients.

When the cellular and chemical parameters between positive and negative detections were compared, most positive patients had an increased CSF protein and WBC levels, the median of WBC count and proteins levels were 41 (0-369) cells $/ \mathrm{mm}^{3}$ and 102.9 (46-214) $\mathrm{mg} / \mathrm{dL}$ respectively, while in negative patients the same parameters were 1 (0-18) cells $/ \mathrm{mm}^{3}$ and 34 (23.1-76.6) $\mathrm{mg} / \mathrm{dL}$, respectively. Regarding the positive detections, the differences between bacterial, fungal and viral detections are shown in Table 3. There was a total agreement for the 11 detections of C. neoformans/gatii between FA-M/E and CrAg, however, four positive results with $\mathrm{CrAg}$ were negative by FA-M/E.

Culture methods detected microorganisms that are not included in the FA-M/E master list, such as Staphylococcus aureus (2), Staphylococcus epidermidis (2), Staphylococcus capitis (2), Elizabethkingia meningoseptica, Streptococcus mitis/oralis. To determine the sensitivity of the test, these organisms were excluded. The operational characteristics of the molecular test are shown in Table 4. The average

Table 4 - Analytical performance of the Biofire ${ }^{\circledR}$ FilmArray ${ }^{\circledR}$ ME in bacterial/fungal detections, Hospital Universitario de San Vicente Fundacion, 2017-2019.

\begin{tabular}{lcccc}
\hline & & \multicolumn{2}{c}{ Culture } & \multirow{2}{*}{ Total } \\
\cline { 2 - 4 } & & + & - & \\
\hline \multirow{2}{*}{ FilmArray ${ }^{\circledR} \mathrm{ME}$} & + & 21 & 33 & 54 \\
& - & 3 & 581 & 585 \\
\hline Total & & 24 & 614 & 638 \\
\hline
\end{tabular}

Sensitivity = 87.50 (IC 95\%: 72.19 - 100.00); Specificity = 94.63 (IC 95\%: 92.76-96.49); Positive predictive value $=38.89$ (IC 95\%: 24.96-52.82); Negative predictive value $=99.49$ (IC 95\%: 98.82-100.00) turnaround time for FA-M/E in the laboratory was $4.5 \mathrm{~h}$, due to administrative procedures.

\section{DISCUSSION}

The novel FA-M/E technique represents a milestone in clinical practice, as its clinical significance in diagnosing meningitis etiology in the Colombian population is still unknown due to its sparse use. However, its implementation constitutes a great opportunity to optimize the turnaround time to release results and to provide novel contributions to the knowledge of meningitis in our country and in Latin America.

In the present study, the male gender was more frequent and the positivity in this group was $64.9 \%$ (63/97), and it is important to note that meningitis in male differs significantly from the ones in females with respect to comorbidities and predictors of adverse clinical outcomes ${ }^{9}$. In addition, it is recognized that men have an increased susceptibility to several pathogens ${ }^{10}$.

The global positivity of the test was $15.2 \%$, with nearly equal proportions of bacteria and viruses detected by FA-M/E, contrasting with previous studies in which viruses were the most frequent, corresponding to around $80 \%$ of detections ${ }^{11-14}$. This could be explained by differences in the studies designs, such as patients' selection criteria, specific population defined by age or clinical condition, antimicrobial therapy, the country's socioeconomic and epidemiological conditions, but even so, the proportion of positive cases found in the present study is in agreement with previous reports, varying from $12-14 \%{ }^{11,15}$.

The most prevalent microorganisms detected during this study were $S$. pneumoniae, C. neoformans/gatti and HSV-1, in $16.6 \%, 11.3 \%, 10.3 \%$ respectively. By bacterial analytes, S. pneumoniae was the most frequent microorganism isolated; this finding agrees with published studies with similar number of samples ${ }^{11-15}$. H. influenzae was 
detected in different age groups despite being a common cause of meningitis in childhood and thewidespread vaccination, which has significantly reduced the incidence of $H$. influenza infections in many low and middle income countries, including Colombia ${ }^{4,16}$. On the contrary, $N$. meningidis was mainly detected in patients younger than 14 years old (7 cases), although all age groups are at risk of invasive meningococcal disease, infants are particularly vulnerable due to the disappearance of passively transferred maternal antibodies ${ }^{17}$. Other bacteria were less frequently detected, such as L. monocitogenes, found in three adults with CSF-negative culture. In one of the three cases, L. monocitogenes was isolated in a blood cultureprobably due to an early hematogen dissemination that probably took place before the meningeal invasion, a process that has been previously described ${ }^{18}$. It is known that $L$. monocytogenes has become the third most frequent pathogen of bacterial meningitis in adults after the vaccination era ${ }^{19}$.

In a multicenter prospective study that used FA-M/E, the overall sensitivity was $85.7 \%$ (HHV-6), $95.7 \%$ (EV) and $100 \%$ for the remaining pathogens; the specificity was above $99 \%$ for all the 14 pathogens ${ }^{13}$. In the present study, for bacterial and fungal analytes, the general sensitivity and specificity were 87.5 (95\% CI: $72.1-100 \%)$ and 94.7 (95\% CI: $92.9-96.6 \%$ ), respectively findings are in line with previous publications that shown values between 60 to $100 \%$ of sensitivity by individual target ${ }^{13,20}$. In this study, CSF cultures were positive in $44.4 \%$ (24/54) of the cases positive by FA-M/E (bacteria/fungi). Disagreements between the molecular detection and cultures results may have been due to limitations in the conventional microbiology as a reference method or if antibiotics have been administered prior to the lumbar puncture ${ }^{1,6}$. FA-M/E has shown to be efficient in detecting bacteria involved in meningitis cases in which CSF culture was negative ${ }^{12}$. On the other hand, negative results can be useful in the differential diagnosis. According to a systematic review, the negative predictive value of FA-M/E has almost $99 \%$ possibility of being correct ${ }^{21}$.

Regarding viral detections, this is the first time that they were routinely performed in clinical practice in this hospital. HSV-1, VZV and HHV-6, with 10, 8, 8 cases, respectively, were the most frequent viral pathogens in a wide range of age. Latency and reactivation are characteristics of viruses from the herpes family, including HSV-2/CMV and they can affect both genders and all age groups, including immunosuppressed patients ${ }^{22}$. Seven cases of HHV-6 were detected in patients under 5 years old, and it is known that around $20 \%$ of emerging room consultations in children are attributable to HHV- ${ }^{23}$. Other FA-M/E studies detected HHV-6 among $1.9-2.7 \%^{13,24}$. CMV was detected in four cases, and the reliability of these positive findings in FA-M/E is unclear, especially in CMV-seropositive patients indicating a past infection or passive transfer of maternal antibodies to infants ${ }^{25}$. An important limitation of FA-M/E is that it does not distinguish latent/active CMV and HHV-6 infections, therefore, clinical information are important for the interpretation of results. Regarding EV detections, they were more frequent in patients under 6-years old, and it has been reported that the majority of aseptic meningitis cases occurred mainly in those under one-year old ${ }^{26}$. Other viruses are present in low frequencies, highlighting the possibility to report new cases that have not been previously described in the region, such as the $\mathrm{HPeV}$, which belongs to the Picornaviridae family and rarely causes meningitis or meningoencephalitis ${ }^{27}$. In this study, it was detected in one case, in a 48-year-old male.

Concerning fungi detections (11 detections), there was not a significant contribution due to a complete agreement of FA-M/E with $\mathrm{CrAg}$, which has been reported in the literature with a sensitivity and specificity around $93-100 \%{ }^{28}$. However, in present study, there were disagreements due to four positive samples by $\mathrm{CrAg}$ that were negative by FA-M/E, as has been previously reported. The explanation for this finding is that the patient can remain positive for years, even after the resolution of the infection ${ }^{28,29}$. A $100 \%$ sensitivity of FA-M/E for newly diagnosed cryptococcosis in an HIV-infected population has been reported ${ }^{30}$.

False negative results for viral targets, were not evaluated as there was not an available comparative testing, however, false-negative FA-M/E results have already been reported with respect to several viruses such as EV, HSV-1, HSV-2, VZV and HHV- $6^{13,14}$ culture, antigen detection, and molecular methods, paired with chemical and cellular analyses. These methods may lack sensitivity or specificity, can take several days, and require significant volume for complete analysis. The FilmArray Meningitis/Encephalitis (ME. A viral load close to the limit of detection and errors caused by incorrect interpretation of the algorithm of the instrument, have been documented ${ }^{30}$.

In present study, the bacterial/fungal detections presented three false-negative results (S. agalactiae, E. coli and C. neoforman/gatiii), and similar findings have been previously described ${ }^{15,20,29,30}$. Factors such as low antigens titers, high PCR crossing thresholds and cultures with growth $<100 \mathrm{CFU} / \mathrm{mL}$ are associated with disagreements that can be attributed to reagents degradation in a kit near to expiration date low fluorescence and incorrect melting signals $^{29,31}$. The trueness analysis of results among all positive detections was not performed, and false positives are a possible scenario, fact that has been previously reported to CMV. In the presence of a bacterial meningitis, 
false positives may be related to the latency of WBC in immunocompetent patients ${ }^{32}$, likewise, in bacterial/fungal detections, false positives may occur due to a number of reasons such as: CSF samples containing low levels of microorganisms that are undetectable in cultures, low pathogens concentration due to earlier antibiotic administration, and the fact that FA-M/E can detect unviable bacteria/fungi ${ }^{1,6}$. Particularly, two studies reported the highest proportion of false positive results to $S$. pneumoniae $(17.5 \text { and } 80 \%)^{13,21}$, and in the present study, there were 16 detections of $S$. pneumoniae, of which six were negative in cultures, and clinical correlations showed that only four of them had a high level of bacterial meningitis suspicion. A positive result should be analyzed carefully and correlated with the medical chart data; repeating the test may be helpful, but a repeated negative result may not necessarily rule out an initial positive result in cases of low pathogen loads ${ }^{33,34}$ other panels have been approved by the FDA, and most recently, the FilmArray meningitis/encephalitis panel (BioFire, Salt Lake City, UT.

In this study, other microorganisms not included in the FA-M/E master list were detected by cultures and it should be noted that molecular assays should be interpreted according to local epidemiology, for example, Klebsiella $s p$, M. tuberculosis, S. epidermidis are not frequently associated with meningitis, but they can be causative agents of meningitis in individuals with some risk factors ${ }^{1,4,9}$. Another aspect to be considered, was the four double detections; even if they may look an advantage, their clinical significance are not clearly understood and require more studies; however, previous reports suggested that reactivations during acute meningitis by other microorganisms can occur ${ }^{34,35}$.

This study has certain limitations, firstly, with respect to viral detections, a suitable comparative marker was not available. Despite this fact, the majority of positive cases were taken into account for the patient's management. Secondly, the low number of positive samples to each of the bacterial microorganisms do not allow an adequate statistical power to evaluate the sensitivity of FA-M/A; additionally, antibiotic administration was not considered in the study variables, therefore, the general impact of antibiotic use on the positivity of the test can be limited. Moreover, other risk factors such as pregnancy, the use of immunosuppressive drugs and further comorbidities were not evaluated. Thirdly, no sample randomization was done as samples were included consecutively. Nevertheless, this is the largest study in the country that included a significant sample size and a long evaluation period.

As the main contribution, this study has a significant proportion of cases (33 detections) that were detected and are not in general diagnosed by traditional tests. Likewise, viral detection was overwhelming, as in the institution in which the study was performed, traditionally viruses are diagnosed by external laboratories, with low sensitivity of methods and prolonged turnaround time, and without the FA-M/E diagnoses might have been delayed or missed. Compared to culture or conventional PCR assays (one pathogen by test), FA-M/E is very faster, which makes it ideal to be introduced in a laboratory routine. In clinical practice, it is often necessary to identify multiple pathogens that may be associated with a certain infectious syndrome. The possibility of detecting multiple targets in a single sample is important when clinical samples are difficult to collect, or are limited in volume, or when different pathogens can cause the same clinical presentation, which poses a greater difficulty to the diagnosis. In addition, the cost versus effectiveness of the test compared to the testing of each pathogen separately is also an advantage of the FA-M/E

In conclusion, the FA-M/E system is able to detect a broad range of pathogens directly in CSF samples with good performance parameters when compared to reference methods, as it has the great advantage of requiring little preparation and handling of the samples.

\section{ACKNOWLEDGMENTS}

To the microbiology and immunochemistry units of the Institution, for their assistance to obtain the laboratory information.

\section{AUTHORS' CONTRIBUTIONS}

Adrián Peñata: conception, design, analysis of data and article writing; Santiago Mesa: laboratory tests and database management; Ana Leal: laboratory tests and database management; Tatiana Castaño: interpretation of data and analysis; Julián Bustamante: interpretation of data and analysis; Sigifredo Ospina: supervised the study, interpretation of data and article writing review. All the authors read and approved the final version of the manuscript.

\section{FUNDING}

The study was funded by the research unit of Hospital Universitario San Vicente Fundación.

\section{REFERENCES}

1. Mount HR, Boyle SD. Aseptic and bacterial meningitis: evaluation, treatment, and prevention. Am Fam Physician. 2017;96:314-22. 
2. Zunt JR, Kassebaum NJ, Blake N, Glennie L, Wright C, Nichols $\mathrm{E}$, et al. Global, regional, and national burden of meningitis, 1990-2016: a systematic analysis for the Global Burden of Disease Study 2016. Lancet Neurol. 2018;17:1061-82.

3. Vora NM, Holman RC, Mehal JM, Steiner CA, Blanton J, Sejvar J. Burden of encephalitis-associated hospitalizations in the United States, 1998-2010. Neurology. 2014;82:443-51.

4. Colombia. Instituto Nacional de Salud. Protocolo de vigilancia en salud pública: meningitis bacteriana y enfermedad meningocócica código 535. Medellín: Ministerio de Salud y Protección Social; 2017. [cited 2020 Sep 15]. Available from: https://www.ins.gov.co/buscador-eventos/Lineamientos/ PRO\%20Meningitis_.pdf

5. Aguirre Muñoz C, Vallejo Zapata IC, Vargas Gutierrez A, Acevedo Arenas L, Uribe Miller GA, Londoño Velez A. Epidemia de meningitis viral en Medellín, Colombia, 2004. Rev Salud Publica Medellín. 2006;1:63-79.

6. Dubos F, Korczowski B, Aygun DA, Martinot A, Prat C, GalettoLacour A, et al. Distinguishing between bacterial and aseptic meningitis in children: European comparison of two clinical decision rules. Arch Dis Child. 2010;95:963-7.

7. Bårnes GK, Gudina EK, Berhane M, Abdissa A, Tesfaw G, Abebe $\mathrm{G}$, et al. New molecular tools for meningitis diagnostics in Ethiopia: a necessary step towards improving antimicrobial prescription. BMC Infect Dis. 2018;18:684.

8. Colombia. Congreso de la república. Resolución numero 8430 de 1993 (Octubre 4). Por la cual se establecen las normas científicas, técnicas y administrativas para la investigación en salud. [cited 2020 Sep 15]. Available from: https://www. minsalud.gov.co/sites/rid/Lists/BibliotecaDigital/RIDE/DE/ DIJ/RESOLUCION-8430-DE-1993.PDF

9. Dharmarajan L, Salazar L, Hasbun R. Gender differences in community-acquired meningitis in adults: clinical presentations and prognostic factors. J Meningitis. 2016;1:106.

10. Klein SL. The effects of hormones on sex differences in infection: from genes to behavior. Neurosci Biobehav Rev. 2000;24:627-38.

11. Boudet A, Pantel A, Carles MJ, Boclé H, Charachon S, Enault C, et al. A review of a 13-month period of FilmArray Meningitis/ Encephalitis panel implementation as a first-line diagnosis tool at a university hospital. 2019;14:e223887.

12. Radmard S, Reid S, Ciryam P, Boubour A, Ho N, Zucker J, et al. Clinical utilization of the FilmArray Meningitis/Encephalitis (ME) multiplex polymerase chain reaction (PCR) assay. Front Neurol. 2019;10:281

13. Leber AL, Everhart K, Balada-Llasat JM, Cullison J, Daly J, Holt S, et al. Multicenter evaluation of BioFire FilmArray Meningitis/Encephalitis panel for detection of bacteria, viruses, and yeast in cerebrospinal fluid specimens. J Clin Microbiol. 2016;54:2251-61.

14. Liesman RM, Strasburg AP, Heitman AK, Theel ES, Patel R, Binnicker MJ. Evaluation of a commercial multiplex molecular panel for diagnosis of infectious meningitis and encephalitis. J Clin Microbiol. 2018;56:e01927-17.

15. Lee SH, Chen SY, Chien JY, Lee TF, Chen JM, Hsueh PR. Usefulness of the FilmArray meningitis/encephalitis (M/E) panel for the diagnosis of infectious meningitis and encephalitis in Taiwan. J Microbiol Immunol Infect. 2019;52:760-8.

16. World Health Organization. Haemophilus influenzae type b (Hib) Vaccination Position Paper - July 2013. Wkly Epidemiol Rec. 2013;88:413-26.

17. Harrison LH. Epidemiological profile of meningococcal disease in the United States. Clin Infect Dis. 2010;50 Suppl 2:S37-44

18. Uribe-Ocampo A, Correa-Pérez S, Rodriguez-Padilla LM, Barrientos-Gómez JG, Orozco-Forero JP. Características clínicas, epidemiológicas y manejo terapéutico de la meningitis pediátrica en dos instituciones de Medellín, Colombia. Univ Salud. 2018;20:121-30.

19. Brouwer MC, van de Beek D, Heckenberg SG, Spanjaard L, de Gans J. Community-acquired Listeria monocytogenes meningitis in adults. Clin Infect Dis. 2006;43:1233-8.

20. Du B, Hua C, Xia Y, Li J, Xie Y, Tao Y, et al. Evaluation of the BioFire FilmArray meningitis/encephalitis panel for the detection of bacteria and yeast in Chinese children. Ann Transl Med 2019;7:437.

21. Tansarli GS, Chapin KC. Diagnostic test accuracy of the BioFire ${ }^{\circledR}$ FilmArray ${ }^{\circledR}$ meningitis/encephalitis panel: a systematic review and meta-analysis. Clin Microbiol Infect. 2020;26:281-90.

22. Azwa A, Barton SE. Aspects of herpes simplex virus: a clinical review. J Fam Plann Reprod Health Care. 2009;35:237-42.

23. González SN, Xochihua DL, Gómez TV, Soto CJ. Encefalitis viral por Herpes virus humano tipo 6: reporte de caso. Rev Enfer Infec Pediatr. 2014;27:420-4.

24. Green DA, Pereira M, Miko B, Radmard S, Whittier S, Thakur K. Clinical significance of human Herpesvirus 6 positivity on the FilmArray Meningitis/Encephalitis Panel. Clin Infect Dis. 2018;67:1125-8.

25. Sorek N, Ashkenazi S, Livni G, Ben-Zvi H. Neisseria meningitidis and cytomegalovirus simultaneous detection in the filmarray meningitis/encephalitis panel and its clinical relevance. IDCases. 2019;17:e0516.

26. Stalkup JR, Chilukuri S. Enterovirus infections: a review of clinical presentation, diagnosis, and treatment. Dermatol Clin. 2002;20:217-23.

27. Calvo C, García-García ML, Arroyas M, Trallero G, Cabrerizo M. Infección por parechovirus 3 en un neonato con fiebre y sospecha de sepsis. An Pediatría (Barc). 2014;81:49-51.

28. Guzmán AM. Importancia del laboratorio en el diagnóstico de las micosis invasoras. Rev Chil Infectol. 2004;21:39-47.

29. O’Halloran JA, Franklin A, Lainhart W, Burnham CA, Powderly W, Dubberke E. Pitfalls associated with the use of molecular diagnostic panels in the diagnosis of cryptococcal meningitis. Open Forum Infect Dis. 2017;4:ofx242 
30. Rhein J, Bahr NC, Hemmert AC, Cloud JL, Bellamkonda S, Oswald C, et al. Diagnostic performance of a multiplex PCR assay for meningitis in an HIV-infected population in Uganda. Diagn Microbiol Infect Dis. 2016;84:268-73.

31. Lee CK, Chiu L, Yan G, Chew KL, Yan B, Jureen R, et al False negative results caused by erroneous automated result interpretation algorithm on the FilmArray 2.0 instrument. Clin Chem Lab Med. 2018;56:e43-5.

32. Studahl M, Ricksten A, Sandberg T, Elowson S, Herner S, Säll C, et al. Cytomegalovirus infection of the CNS in noncompromised patients. Acta Neurol Scand. 1994;89:451-7.
33. Dien Bard J, Alby K. Point-counterpoint: meningitis/encephalitis syndromic testing in the clinical laboratory. J Clin Microbiol. 2018;56:e0018-18.

34. Ericsdotter AC, Brink M, Studahl M, Bengnér M. Reactivation of herpes simplex type 1 in pneumococcal meningitis. J Clin Virol. 2015;66:100-2.

35. Labská K, Roubalová K, Pícha D, Marešová V. Presence of herpesvirus DNA in cerebrospinal fluid of patients with tickborne encephalitis and enteroviral meningoencephalitis. J Med Virol. 2015;87:1235-40. 